\title{
Theoretical Research on the Flight of Onion Seeds under Discharge from the Seeding Unit
}

\author{
V. M. Turdaliev, B. Igrashev, G. U. Makhkamov, A. A. Qosimov
}

\begin{abstract}
One of the most important issues of sowing small-seeded crops (an example of onions) is considered. The method of sowing has a great influence on crop yields. The choice of planting method is due to the need for a more uniform distribution of plants over the field area in order to optimize the conditions for their development. Studying the movement of seeds during the sowing process is the most important task. Because, the object of sowing is the seeds. The article provides an analysis of previous work on the precision sowing of small seed crops. And also, the flight and the trajectory of the seeds from the ejection window to the bottom of the groove were studied theoretically. In research methods of higher mathematics were used, in which it was possible to obtain the necessary equation. Based on the numerical solution of the obtained equations, graphs are constructed that determine the path of onion seeds on the corresponding $X$ and $Y$ axes. It can be seen from the graphs that the flight path of the seeds changes according to the parabola law.
\end{abstract}

Keywords: Seeds, onions, movements, speed, trajectory of a small-seeded crop, sowing apparatus.

\section{INTRODUCTION}

$\mathrm{T}$

he main task of improving the processes and working bodies of agricultural machines is to increase crop yields [1, 2 , 3]. Sowing seeds is the most important stage in the cultivation of crops. Sowing should provide the most favorable condition for seed germination and further development, which helps to increase field germination and crop yields. However, in the field it is difficult to provide piece crops and to determine the incorporation of small-seeded vegetables.

Revised Manuscript Received on February 15, 2020

* Correspondence Author

Voxidjon Maxsudovich Turdaliyev, Doctor of Technical of Sciences, Docent, Department of General Technical Disciplines, Namangan Engineering Construction Institute, Namangan, Uzbekistan. Email: vox-171181@mail.ru

Baxrom Irgashev, Doctor of Philosophy in physical and Mathematical, Docent, Department of higher Mathematics, Namangan Engineering Construction Institute, Namangan, Uzbekistan., Email: bahrom75@mail.ru

Gulomjon Usmonjonovich Maxkamov, Scientific Applicant, Department of General Technical Disciplines, Namangan Engineering Construction Institute, Namangan, Uzbekistan.

Email: Arsmgu8286@Umail.Uz

Azamjon Adixamjonovich Qosimov, Scientific Applicant, Department of General Technical Disciplines, Namangan Engineering Construction Institute. Email: aaqosimov85@gmail.com

(C) The Authors. Published by Blue Eyes Intelligence Engineering and Sciences Publication (BEIESP). This is an open access article under the CC BY-NC-ND license (http://creativecommons.org/licenses/by-nc-nd/4.0/)
Seeds with an average diameter of less than $3 \mathrm{~mm}$, including most seeds of vegetables, flowers and canola, such as tomatoes, peppers, radishes, carrots and other seeds of vegetables, with flat and fleecy surfaces. Therefore, it is difficult to develop an accurate seeder for small seeded crops. In accordance with agricultural requirements, accurate sowing can provide the most rational distribution of seeds in the field [4]. Optimal plant development requires an optimal planting area for each individual plant. Accurate sowing of seeds, even distance between plants, the same depth of sowing and the best conditions for the growth and development of seeds can save a lot of seeds and ensure a stable crop and a high crop of crops. [5, 6].

The work shows that the correct seeding rate per unit area is vital for productivity. In order to evaluate the desired seeding rate, the number of seeds dropped must be monitored in real time. A seed quantity sensor has been developed that allows small seeds to pass stably through a ray of light. The developed sensor can be used for accurate and reliable control of the number of seeds for the precise sowing of small seeds [7].

In the literature, the influence of various factors on the uniformity of sowing is considered. It was found that a seed drop height of $8 \mathrm{~mm}$ invariably provides a better sowing structure than a drop height of $15 \mathrm{~mm}$ with an accurate vacuum seeder. They recommended that the metering device on the seeder be located as low as possible, and that the seeds fall freely to the bottom of the soil trench. They stated that the variability of the distance between the seeds with the help of a precision vacuum seeder increases with increasing forward speed. They found that a forward speed of $1 \mathrm{~m} / \mathrm{s}$ provides a better sowing structure than 1.5 and $2.0 \mathrm{~m} / \mathrm{s}$ for accurate sowing of melon and cucumber seeds [8].

\section{MATERIALS AND METHODS}

According to the analysis of the study, the following can be attributed to the main factors influencing the uniformity of seed distribution:

- quality of dosing of seeds by the sowing apparatus;

- the stability of the flight time and the path of the seeds from the exhaust window to the bottom of the groove;

- redistribution of seeds after hitting the soil.

In studies, much attention is paid to the justification of the pinch angle and the place of the ejector, since the crushing of seeds depends on these parameters, speed and direction of flight. In the cells of a mechanical sowing device, the seeds are placed freely and they can be ejected without an ejector. 
There is a significant difference in the trajectories and flight speeds of seeds ejected by the ejector and released freely. According to the analysis of studies, it is possible to proceed with free unloading of the cells, in which the negative influence of the ejector on the flight path of the seeds is eliminated and their crushing is reduced.

Based on the above, we studied theoretically the flight and the path of the seeds from the discharge window to the bottom of the groove.

Onion seeds at the exit from the sowing apparatus has an initial speed of $v_{0 x}$. Because, the movement is transmitted from the support wheel using a chain drive to the metering unit. In this case, we take the initial speed $v_{0 x}$ of onion seeds equal to the linear speed of the sowing apparatus.

\section{RESULTS AND DISCUSSION}

We begin the study to determine the linear speed of the sowing apparatus.

According to the scheme in fig. 2, we determine the angular velocity of the support wheel

$$
\omega_{1}=\frac{V_{a}}{R},
$$

where $V_{a}$ - seeder speed, $\mathrm{m} / \mathrm{s} ; R$ - radius of the support wheel, all points of the link. [9, 10]. Therefore, we will take the angular velocity of the drive sprockets equal to the angular velocity of the support wheel. In this case, the angular

$$
\omega_{2}=\frac{\omega_{1}}{u},
$$

where $\omega_{1}$ - angular velocity of the leading sprocket, rad/s; $u$-gear ratio of the chain transmission. Determine the linear speed of the metering unit

$$
V_{2}=\omega_{2} R_{2} \text {, }
$$

where $\omega_{2}$ - angular velocity of the sowing apparatus, $\mathrm{rad} / \mathrm{s} ; R_{2}$ - radius of the sowing apparatus, $\mathrm{m}$.

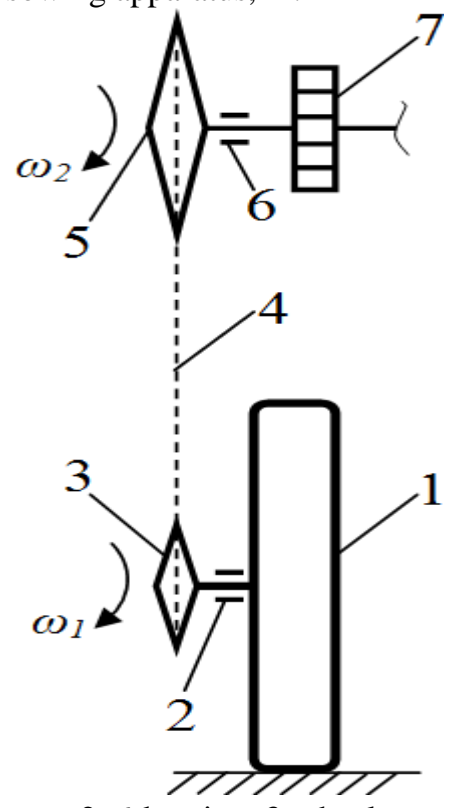

1-wheel support, 2, 6-bearing, 3-wheel sprocket; 4-flail;

5-driven sprocket; 7-disc meter

Fig. 2. The scheme of the drive sowing apparatus $\mathrm{m}$ It is known that the angular velocity of a link is the same at velocities of the driven sprocket and sowing apparatus are determined as follows

The movement of onion seeds was investigated as follows (fig. 2.).

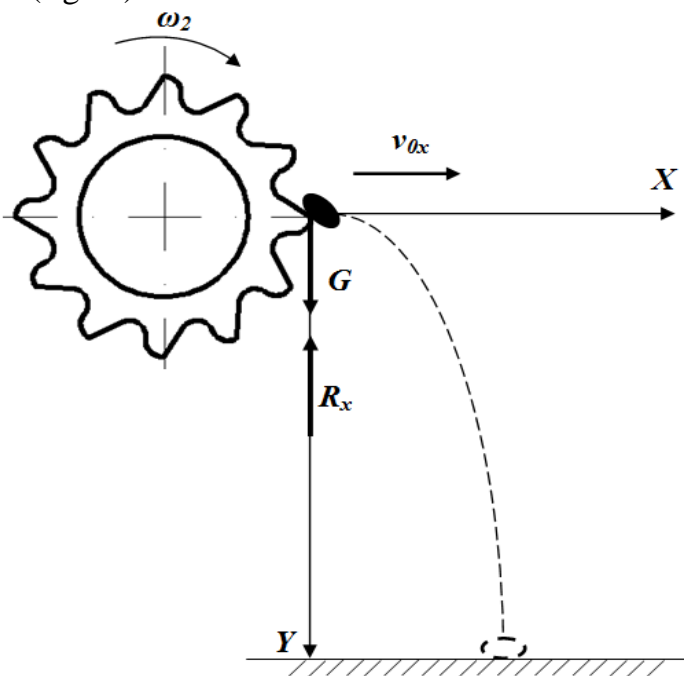

Fig. 2. The scheme for determining the trajectories of onion seeds during the release

If we take into account air resistance when studying the movement of onion seeds, according to figure 2, we write the equation for the movement of seeds

$$
\begin{aligned}
& m \ddot{x}=-R_{x}, \\
& m \ddot{y}=G-R_{x},
\end{aligned}
$$

where $m$ - mass of onion seeds, $\mathrm{kg} ; R_{x}$ - air resistance force, $\mathrm{N}$; G-gravity, N.

The forces of gravity and air resistance are defined as follows [11]

$$
\begin{gathered}
G=m g, \\
R_{x}=\frac{1}{2} \mu \oint v^{2},
\end{gathered}
$$

where $g$ - gravitational acceleration, $\mathrm{m} / \mathrm{s}^{2} \cdot \mu$ - drag coefficient depending on the shape of the body; $\varsigma$-density of air, $\mathrm{kg} / \mathrm{m}^{3} ; S$ - midellar surface of onion seeds, $m^{2} ; v$-speed of onion seeds, $\mathrm{m} / \mathrm{s}$.

Considering (6) and (7), we write the system of equations (4) and (5) as follows

$$
\begin{gathered}
m \ddot{x}=-\frac{1}{2} \mu \oint v^{2} \\
m \ddot{y}=m g-\frac{1}{2} \mu \oint v^{2}
\end{gathered}
$$

Or

$$
\begin{array}{r}
m \ddot{x}=-\frac{1}{2} \mu \oint \dot{x}^{2} \\
m \ddot{y}=m g-\frac{1}{2} \mu \oint \dot{y}^{2}
\end{array}
$$

Determine the movement of onion seeds along the $X$ axis using equation (10). Given that, we write equation (10) 


$$
m v_{x}^{\prime}=-\frac{1}{2} \mu \oint v_{x}^{2}
$$

Dividing the two sides of equation (12) by the mass of the onion, we obtain the following

$$
\frac{d v_{x}}{v_{x}^{2}}=-\frac{\mu \oint}{2 m} d t
$$

To determine the speed of onion seeds along the $X$ axis, we integrate equation (13) once

$$
-\frac{1}{v}=-\frac{\mu \oint}{2 m} t+C_{1}
$$

For $t=0, x=0$ and $\dot{x}(0)=v_{0 x}$.

Then

$$
C_{1}=\frac{1}{v_{0 x}}
$$

And also, equation (14) forms the following form

$$
\frac{1}{v}=\frac{\mu \oint v_{0 x} t+2 m}{2 m v_{0 x}}
$$

From equation (15) we find $v$

$$
v_{x}=\dot{x}(t)=\frac{2 m v_{0 x}}{\mu S v_{0 x} t+2 m}
$$

To determine the movement of onion seeds along the $X$ axis, we integrate equation (16) once and get

$$
x=\frac{2 m v_{0 x}}{\mu \varsigma v_{0 x}} \ln \left(\mu \oint v_{0 x} t+2 m\right)+C_{2}
$$

For $t=0, x=0$. Therefore

$$
C_{2}=-\frac{2 m}{\mu \varsigma} \ln (2 m)
$$

Given equation (18), we can write equation (17) as follows

$$
x=\frac{2 m}{\mu \varsigma} \ln \left(\mu \oint v_{0 x} t+2 m\right)-\frac{2 m}{\mu \varsigma} \ln (2 m)
$$

Given that, $\ln (x+\Delta x)-\ln (x)=\ln \frac{x+\Delta x}{x}$, we write equations (19) as follows

$$
x=\frac{2 m}{\mu \varsigma S} \ln \left(\frac{\mu \varsigma S v_{x 0} t}{2 m}+1\right)
$$

We determine the movement of onion seeds along the $\mathrm{Y}$ axis using equation (11). To simplify the equation, divide the two sides by the mass $m$ of onion seeds. In this case, we obtain

$$
\ddot{y}=g-\frac{1}{2 m} \mu \varsigma S \dot{y}^{2}
$$

Given that, $\dot{y}=v_{y}(t)$, and also for convenience, the solution to the problem we add a note that $\frac{\mu \oint}{2 m}=A^{2}$ Moreover, equation (21) takes this form

$$
v_{y}^{\prime}=\frac{d v_{y}}{d t}=g-A^{2} v_{y}^{2}
$$

From equation (22) we define $d t$

$$
d t=\frac{d v_{y}}{g-A^{2} v_{y}^{2}}
$$

From here

$$
\int \frac{d v_{y}}{g-\left(A v_{y}\right)^{2}}=t+\ln C_{3}
$$

Given that, $\int \frac{d x}{a^{2}-x^{2}}=\frac{1}{2 a} \ln \frac{a+x}{a-x}$, we write equation (24) as follows

$$
\begin{gathered}
\frac{1}{2 A \sqrt{g}} \ln \frac{\sqrt{g}+A v_{y}}{\sqrt{g}-A v_{y}}=t+\ln C_{3} \\
\ln \frac{\sqrt{g}+A v_{y}}{\sqrt{g}-A v_{y}}=2 A t \sqrt{g}+\ln C_{3} \\
\frac{\sqrt{g}+A v_{y}}{\sqrt{g}-A v_{y}}=C_{3} e^{2 A t \sqrt{g}} \\
\sqrt{g}+A v_{y}=C_{3} \sqrt{g} e^{2 A t \sqrt{g}}-C_{3} A v_{y} e^{2 A t \sqrt{g}} \\
A v_{y}\left(1+C_{3} e^{2 A t \sqrt{g}}\right)=C_{3} \sqrt{g} e^{2 A t \sqrt{g}}-\sqrt{g} \\
v_{y}=\frac{\sqrt{g}}{A} \cdot \frac{C_{3} e^{2 A t \sqrt{g}}-1}{C_{3} e^{2 A t \sqrt{g}}+1}
\end{gathered}
$$

Or

$$
v_{y}=\frac{\sqrt{g}}{A} \cdot \frac{e^{2 A t \sqrt{g}}-C_{3}}{e^{2 A t \sqrt{g}}+C_{3}}
$$

Since $t=0, y=0$ and $\dot{y}(0)=v_{0 y}=0$, then $C_{3}=1$ Therefore, equation (31) takes the form

$$
v_{y}=\frac{\sqrt{g}}{A} \cdot \frac{e^{2 A t \sqrt{g}}-1}{e^{2 A t \sqrt{g}}+1}
$$

To solve the problem, multiply the right side of equation (32) by $e^{-A t \sqrt{g}}$. Then

$$
v_{y}=\frac{\sqrt{g}}{A} \cdot \frac{e^{A t \sqrt{g}}-e^{-A t \sqrt{g}}}{e^{A t \sqrt{g}}+e^{-A t \sqrt{g}}}
$$

Given the hyperbolic function, that $\operatorname{sh} x=\frac{e^{x}-e^{-x}}{2}$, $\operatorname{ch} x=\frac{e^{x}+e^{-x}}{2}$ and thx $=\frac{\operatorname{sh} x}{\operatorname{ch} x}=\frac{e^{x}-e^{-x}}{e^{x}+e^{-x}}[12,13,14]$

Determine the speed

$$
v_{y}=\dot{y}(t)=\frac{\sqrt{g}}{A} \cdot \operatorname{th}(A t \sqrt{g})
$$

To determine the movement of onion seeds along the $\mathrm{Y}$ axis, we integrate equation (33) once and get 


$$
y(t)=\frac{\sqrt{g}}{A} \int \operatorname{th}(A t \sqrt{g}) d t+C_{4}
$$

Or

$$
y(t)=\frac{\sqrt{g}}{A} \int \frac{\operatorname{sh}(A t \sqrt{g})}{\operatorname{ch}(A t \sqrt{g})} d t+C_{4}
$$

Given that $(\operatorname{sh} x)^{\prime}=\operatorname{ch} x$. We write equation (36) as follows.

$$
\begin{aligned}
& y(t)=\frac{\sqrt{g}}{A} \frac{1}{A \sqrt{g}} \int \frac{d \operatorname{ch}(A t \sqrt{g})}{\operatorname{ch}(A t \sqrt{g})}+C_{4}=\frac{1}{A^{2}} \ln \operatorname{ch}(A t \sqrt{g})+C_{4} \\
& \text { For } t=0, y=0 \text { and } \operatorname{ch}(A 0 \sqrt{g})=\frac{e^{0}+e^{0}}{2}=1 \text {. Then }
\end{aligned}
$$

$C_{4}=0$ and equation (37) takes the following form

$$
y=\frac{2 m}{\mu \varsigma S} \ln c h\left(\sqrt{\frac{\mu \varsigma S g}{2 m} t}\right)
$$

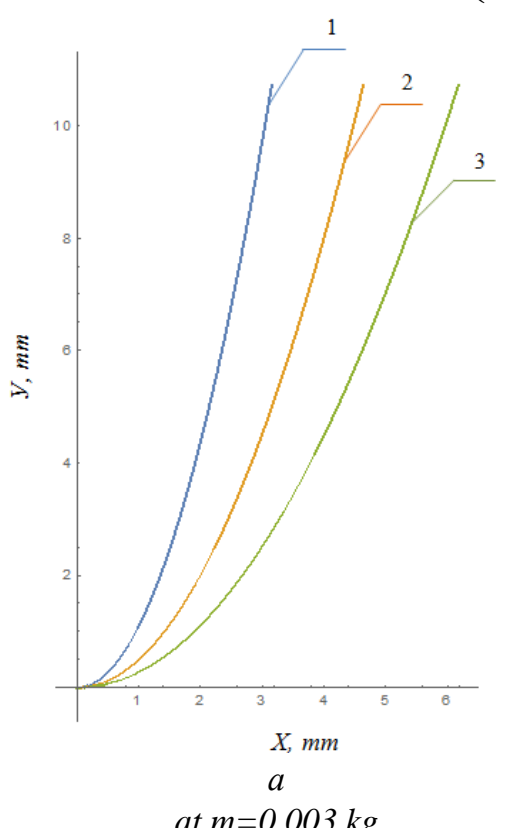

at $m=0.003 \mathrm{~kg}$

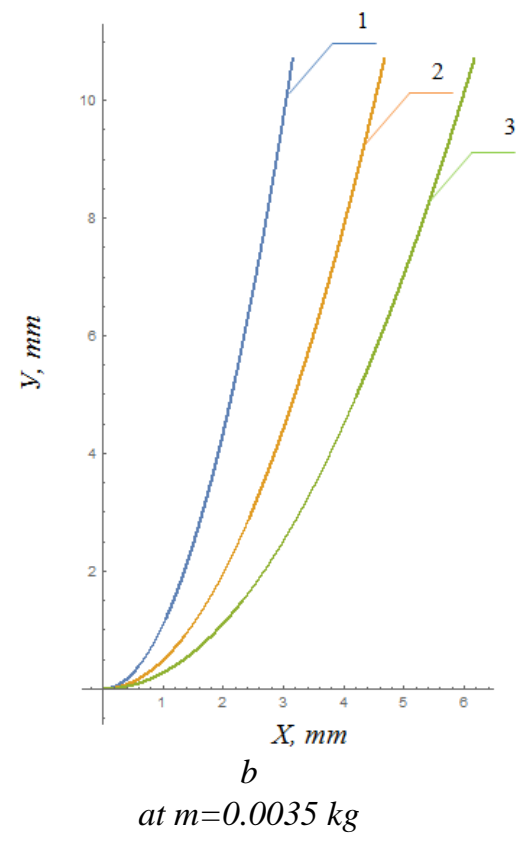

$1-v_{x o}=1.4 \mathrm{~m} / \mathrm{s} ; 2-v_{x o}=2.1 \mathrm{~m} / \mathrm{s} ; 3-v_{x o}=2.8 \mathrm{~m} / \mathrm{s}$
To determine the movement of onion seeds along the $\mathrm{X}$ and $\mathrm{Y}$ axes, we will solve equations (20) and (38) numerically in the «Wolfram Mathematica 10» program. The solution was carried out with the following numerical values of the parameters: $m=(0.003 ; 0.0035 ; 0.004) \mathrm{kg} ; v_{x 0}=(1.4$; $2.1 ; 2.8) \mathrm{m} / \mathrm{s} ; \mu=0.25$ (temperature of the circle at $10-15^{\circ} \mathrm{C}$ ); $\varsigma=1.25 \mathrm{~kg} / \mathrm{m}^{3} ; S=0,0006 \mathrm{~m}^{2} ; g=9.8 \mathrm{~m} / \mathrm{s}^{2} ; t \in[0 ; 1] \mathrm{s}$.

Based on the numerical solution of equations (20) and (40), the trajectories of onion seeds on the corresponding axes were obtained (see fig. 3). It can be seen from the obtained graphs that the flight path of the seeds will change according to the parabola law, and with an increase in the initial seed speeds, the value of $X$ and $Y$ will increase in a non-linear pattern. But, at the same time, with an increase in seed weight from $0.003 \mathrm{~kg}$ to $0.004 \mathrm{~kg}$, the path of flight of onion seeds slightly increases than. This is because the initial seed speed directly affects the flight of seeds.

Fig. 3. The trajectory of the fall of onion seeds when ejected from the sowing apparatus

From the obtained graphs it can be seen that the flight path of the seeds changes according to the law of the parabola and with an increase in the initial speeds of the seeds, the value of $X$ and $Y$ increases in a non-linear pattern. But, at the same time, with an increase in seed weight from $0.003 \mathrm{~kg}$ to 0.004 $\mathrm{kg}$, the path of flight of onion seeds slightly increases than. This is because the initial seed speed directly affects the flight of seeds. It can be noted that the initial speed of the seeds is $1.4 \mathrm{~m} / \mathrm{s}$, then the flight of the onion along the $X$ axis will be up to $3 \mathrm{~cm}$, with the $Y$ axis $10 \mathrm{~cm}$. So, with the initial speed of $2.8 \mathrm{~m} / \mathrm{s}$, the flight of the onion along the $X$ axis will be up to 6 $\mathrm{cm}$, with an axis of $10 \mathrm{~cm}$.

\section{CONCLUSION}

As a result of this study, a differential equation was obtained to determine the movement of onion seeds. In the work, methods of higher mathematics are used, in which it is possible to obtain the necessary equation. Based on the numerical solution of the obtained equations, graphs are constructed that determine the path of onion seeds on the corresponding $\mathrm{X}$ and $\mathrm{Y}$ axes. It can be seen from the graphs that the flight path of the seeds changes according to the parabola law. From the results of this study, you can use it for designing the design of sowing apparatuses and fertilizer pipelines of seeders.

\section{REFERENCES}

1. Ismet O., Adnan D., Arzu Y. An evaluation of seed spacing accuracy of a vacuum type precision metering полет лука по оси $\mathrm{X}$ будет до $3 \mathrm{~cm}$, unit based on theoretical considerations and experiments // Turk J Agric For, 36 (2016). Pp. 133-144 (doi:10.3909/tar-1010-1316).

2. Ani O.A., Uxoejinwa B.B., Anocnili N.F. Design, construction and evaluation of a vertical plate maize seed planter for gardens and small holder farmers // Nigerian Journal of Technology, vol.35, No. 3, July 2016. pp. 647-655 (dx.doi.org/10.4314/njt.v35i3.25). 
3. Liu L., Yang H., Ma Sh. Experimental study on performance of pneumatic seeding system // Int J Agric \& Bio Eng., vol.9, No. 6, November 2016. pp. 84-90. (doi:10.3965/j.ijabe.20160906.2129).

4. X.Jin, Q.W.Li, K.X. Zhao, B.Zhao, Z.T.He, Z.M.Qiu. Development and test of an electric precision seeder for small-size vegetable seeds // Int J Agric \& Biol Eng, 2019; 12(2): 75-81.

5. M.Demmel, O.Hahnenkamm, G.Kormann, M.Peterreins. Gleichstandsaat bei Silomais - Ergebnisse aus zwei Versuchsjahren. LANDTECHNIK. 55, 3 (Juni 2000), pp. 210-211 (doi.org/10.15150/lt.2000.1881).

6. H.Önen, S.Farooq, S.Tad, C.Özaslan, H.Gunal, B.S.Chauhan (2018) The Influence of Environmental Factors on Germination of Burcucumber (Sicyos angulatus) Seeds // Implications for Range Expansion and Management. Weed Sci. doi: 10.1017/wsc.2018.20.

7. W.Liu, J.Hu, X.Zhao, H.Pan, I.A.Lakhiar, W.Wang, J.Zhao. Development and Experimental Analysis of a Seeding Quantity Sensor for the Precision Seeding of Small Seeds (doi:10.3390/s19235191).

8. D. Karayel, A. Özmerzi. Effect of tillage methods on sowing uniformity of maize // Canadian biosystems engineering, Volume 44 2002, $223-226$ (https://www.researchgate.net/publication/267548475_Effect_of_tilla ge_methods_on_sowing_uniformity_of_maize).

9. S.H.Dler, I.Hamarash. Calculation of angular velocity, angular acceleration and torque of two common point rigid bodies using IMU // Journal of Applied and Physical Sciences, 2017, 3(2): 58-64 (DOI: 10.20474/japs-3.2.3).

10. D.Hroncová, I.Delyová1, P.Frankovský. Kinematic analysis of mechanisms using MSC Adams // Applied Mechanics and Materials, Vol. 611, pp 83-89 (DOI: 10.4028/www.scientific.net/AMM.611.83).

11. Ch.H.Belgacem. Analysis of projectile motion with quadratic air resistance from a nonzero height using the Lambert W function // Journal of Taibah University for Science, 2016 (dx.doi.org/10.1016/j.jtusci.2016.02.009).

12. W.R.Miranda. Note: hyperbolic function or equation of the hyperbola? /I Research (PDF Available) March 2016 (DOI: 10.13140/RG.2.1.1239.5287)

13. Ch. Chen, J.Sandor. Chains related to trigonometric and hyperbolic functions and inverse trigonometric and hyperbolic functions // Journal of Mathematical Inequalities, Volume 7, Number 4 (2013), 569-575 (doi: 10.7153/jmi-07-53)

14. Ch. Chen, J.Sandor. Sharp inequalities for trigonometric and hyperbolic functions // Journal of Mathematical Inequalities, Volume 9, Number 1 (2015), 203-217 (doi: 10.7153/jmi-09-19).

\section{AUTHORS PROFILE}

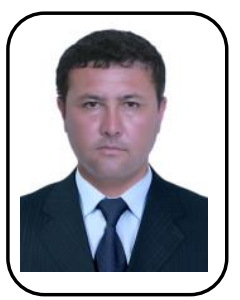

Voxidjon Maxsudovich Turdaliyev - Doctor of technical of Sciences, docent, Department of general technical disciplines, Namangan engineering construction institute, Republic of Uzbekistan, Namangan city, Islam Karimov street 12. Email vox-171181@mail.ru phone: +998973359339.

Baxrom Irgashev - Doctor of Philosophy in physical and mathematical, docent, Department of higher mathematics, Namangan engineering construction institute, Republic of Uzbekistan, Namangan city, Islam Karimov street 12. Email: bahrom75@mail.ru

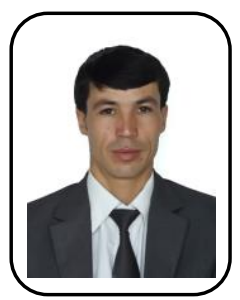

Gulomjon Usmonjonovich Maxkamov scientific applicant, Department of general technical disciplines, Namangan engineering construction institute, Republic of Uzbekistan, Namangan city, Islam Karimov street 12. Email: arsmgu8286@umail.uz phone: +998939382588.

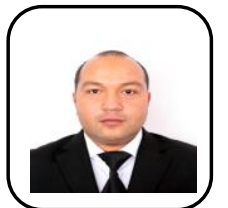

Azamjon Adixamjonovich Qosimov - scientific applicant, Department of general technical disciplines, Namangan engineering - construction institute, Republic of Uzbekistan, Namangan city, Islam Karimov street 12. Email: aaqosimov85@gmail.com phone: +998973752808 